\title{
Centralized Control of Distribution Networks with High Penetration of Renewable Energies
}

\author{
Fco. Javier Zarco-Soto ${ }^{(D)}$, Pedro J. Zarco-Periñán and Jose L. Martínez-Ramos * \\ Departamento de Ingeniería Eléctrica, Escuela Técnica Superior de Ingeniería, Universidad de Sevilla, \\ 41092 Sevilla, Spain; fjzarco@outlook.com (F.J.Z.-S.); pzarco@us.es (P.J.Z.-P.) \\ * Correspondence: jl.martinez.ramos@gmail.com; Tel.: +34-629-503-156
}

Citation: Zarco-Soto, F.J.;

Zarco-Periñán, P.J.; Martínez-Ramos,

J.L. Centralized Control of

Distribution Networks with High Penetration of Renewable Energies. Energies 2021, 14, 4283. https:// doi.org/10.3390/en14144283

Academic Editors: Adolfo Dannier and André Madureira

Received: 31 May 2021

Accepted: 13 July 2021

Published: 15 July 2021

Publisher's Note: MDPI stays neutral with regard to jurisdictional claims in published maps and institutional affiliations.

Copyright: (c) 2021 by the authors. Licensee MDPI, Basel, Switzerland. This article is an open access article distributed under the terms and conditions of the Creative Commons Attribution (CC BY) license (https:/ / creativecommons.org/licenses/by/ $4.0 /)$.

\begin{abstract}
Distribution networks were conceived to distribute the energy received from transmission and subtransmission to supply passive loads. This approach, however, is not valid anymore due to the presence of distributed generation, which is mainly based on renewable energies, and the increased number of plug-in electric vehicles that are connected at this voltage level for domestic use. In this paper the ongoing transition that distribution networks face is addressed. Whereas distributed renewable energy sources increase nodal voltages, electric vehicles result in demand surges higher than the load predictions considered when planning these networks, leading to congestion in distribution lines and transformers. Additionally, centralized control techniques are analyzed to reduce the impact of distributed generation and electric vehicles and increase their effective integration. A classification of the different methodologies applied to the problems of voltage control and congestion management is presented.
\end{abstract}

Keywords: voltage control; congestion management; distribution network; renewable energy source; plug-in electric vehicle

\section{Introduction}

Traditional power systems are based on fossil-fuel generation mainly connected at transmission networks, far from the end-users connected at low voltage [1]. Around this concept, the current power systems were developed based on synchronous generators to meet demand and quality requirements. However, the need for reducing the share of fossil fuels from the energy mix has led to the development of more efficient technologies. There are several approaches to generating electricity according to the available resources, which can be classified into renewable and non-renewable technologies. The former include solar photovoltaic, wind turbines, fuel cells, small hydro, biomass, geothermal, and ocean (waves and tidal) energy systems, whereas distributed non-renewable technologies include diesel reciprocating engines, gas reciprocating engines, and gas turbines [2]. Although some of these technologies are not intrinsically efficient, it is possible to increase the overall efficiency by combining electric generation with useful heat and cooling, i.e., cogeneration and trigeneration.

In particular, renewable energy sources have become an unstoppable trend [3] within the last decade, and this is challenging for all electric power systems at all voltage levels. Although part of this generation is still connected at high voltage (e.g., offshore wind farms in the North Sea), distributed renewable energy sources (DRES) have become particularly suitable for being connected close to end-users due to their intrinsic emission-free characteristics. The available resources in each region determine which technology can be used. Whereas geothermal and ocean systems are limited, solar photovoltaic and wind turbines are more widespread. In fact, photovoltaics is considerably increasing its presence in low voltage networks. Its modularity, compactness, and noiseless performance, in conjunction with its falling price, have resulted in an attractive solution for being mounted on 
rooftops in residential areas for self-consumption. In this sense, DRES are connected close to end-users in urban or rural areas, bringing several advantages, along with challenges.

On the one hand, it is becoming increasingly lucrative for private investors to invest in power plants connected at distribution levels and for small investors to install DRES in their homes to reduce their bills [4]. While their power consumption decreases, the energy excess can also be sold and injected upstream into the grid. Although the intermittency of natural resources makes it difficult to meet demand if no energy storage system is available, several studies aim at solving these issues by incentivizing consumers to modify their behaviors to meet power generation [5]. Additionally, system efficiency undoubtedly increases if power is located near to consumption nodes; however, power excess may be then fed back into the transmission grid and transported over longer electrical distances, increasing power losses [6].

On the other hand, renewable energy production directly relies on the weather, and thus it can vary considerably within a few minutes, e.g., the primary source of photovoltaic panels is sunlight that is very sensitive to clouds; therefore, a sunny day can become cloudy and affect the energy production within the network. To tackle this problem, combined solutions of DRES and battery storage to smooth power injection can be considered. Even though end-users are not typically aware of this issue, this kind of solution is gaining popularity since energy excess can be stored to be used later [7], and also motivated by the falling price of batteries [8]. Moreover, voltage control is affected, since the voltage profile changes. Traditional distribution networks have only had passive loads connected and no generation, thus the power flow could be considered unidirectionally from the distribution substation to downstream loads. The voltage drop within the network could then be estimated by means of the current demanded, since the impedances of distribution lines and transformers are design parameters. Therefore, voltage control was mainly reduced to maintain the voltage at substations at a certain value, so that the voltage within the distribution network met the limits. DRES change this paradigm, however. Injecting power increases the voltage at the node where the generator is connected and at surrounding nodes. Since traditional distribution networks only measure voltage at the secondary substation, voltage limits could be surpassed without the knowledge of the system operator. In this regard, there have been several studies focusing on improving voltage control in distribution networks with a high penetration of DRES.

The electrification of the transport sector is another pillar in reducing the dependency on fossil fuels. Currently, there are several solutions based on different technologies, including hybrid vehicles that combine internal combustion engine with an electric motor, fueled electric vehicles, usually based on hydrogen fuel cells, and battery electric vehicles [9]. These categories present many other variants and subtypes that show the efforts of engineers and scientists to develop viable electric vehicle technologies. In this sense, plug-in electric vehicles (PEVs) need to connect to an electrical grid to charge their batteries. In contrast to renewable generation that is connected at different voltage levels, PEVs can only charge at voltage levels admissible for domestic use, which is provided through distribution networks.

PEVs create heavy loads, typically higher than the demand estimations considered when distribution networks were planned. The current trend is, indeed, to spread out vehicle chargers geographically, leading to unaffordable reinforcements. In this way, efficient controls to manage vehicle charging and discharging are being developed to help increasing PEV integration.

Distribution networks have been traditionally planned and operated under the socalled fit-and-forget premise [10]. Operation was mainly determined during the planning stage by the adequate sizing of conductors, transformers, and equipment, according to the current and forecasted power demand. Then, by controlling voltage at the upstream substations, the voltage within the network was maintained within these bounds by estimating the voltage drop according to the flowing current and feeder impedance. The introduction of DRES, however, directly affects this traditional operation. If only the 
voltage in the upstream substation is controlled, the distribution system operator would not detect overvoltages in far nodes, near to the DRES. Additionally, the current trend towards fast charging modes makes PEVs behave as a heavy mobile load with a random space-time characteristic [11]. If no remedial actions are considered, this may result in congestion in distribution lines and transformers, as well as in undervoltages.

Therefore, classical control strategies present several drawbacks for operating networks in the presence of DRES: power flows are considered unidirectional from distribution substation to consumption nodes; measurements are obtained at the substation; and downstream generation is not considered, since the network is assumed to be passive. Furthermore, since the demand increase is expected to be homogeneous, both spatial and temporal increases due to PEVs are not considered. In conclusion, the fit-and-forget premise is no longer acceptable in distribution networks, and it is necessary to move towards new operation procedures.

Along these lines, the aim of this paper was to analyze the ongoing change of paradigm to active distribution networks. The traditional operational philosophy was studied to present the current state of distribution networks and their evolution with this new paradigm. Then, a review of centralized control algorithms to improve DRES and PEV penetration is presented, which is a combination of methods for voltage control and congestion management. A final table that classifies these methodologies is also presented. This manuscript is organized as follows. Section 2 addresses classical control strategies for passive distribution networks, where only loads are connected, and the fit-and-forget premise is applied. Then, in Section 3, centralized methodologies are analyzed to tackle the upcoming problems due to DRES and PEVs. Finally, Section 4 sums up the conclusions of this study.

\section{Classical Control Strategies in Passive Distribution Networks}

Electric power system planning defines the infrastructure and its size necessary to transmit electrical energy to consumers according to certain requirements, defined by regional, national, and international standards. Then, through real-time operation [12] the electrical magnitudes are maintained between the predetermined limits by correcting for the consequences of demand evolution and nonpredictable events, also known as contingencies.

The operation of traditional power systems that has stood the test of time is based on centralized generation and relatively disperse loads. Generation was connected at a high voltage level to transmission networks that were developed to transmit effectively and efficiently large amounts of energy. For that purpose, transmission networks have received considerable investments that allow one to monitor all nodes and to control the system in real-time. To reach all users, these networks ramified into distribution networks with decreasing voltage level. The high number of consumers, which are sometimes spread out, and the absence of generation, has led to the development of classical distribution networks mainly by considering economic criteria.

The topology of distribution networks typically depends on the density of the consumers connected. Urban areas group several clients in a limited space, whereas they are remarkably widespread in rural zones. In that sense, any quality issue that takes place within the former (e.g., supply interruption) affects a lot of users, thus reducing considerably the power quality indexes that could affect the remuneration of the distribution utility. As a result, the network is planned to supply energy to loads through different paths because the demand density is high enough; in other words, the system is meshed or, at least, some loops are created. On the contrary, to reduce costs, the topology of distribution networks in rural zones is radial, since the number of consumers is substantially lower. However, the operation is similar in both cases, as it is simplified at medium and low voltage by opening certain lines to have a radial system, if needed. Then, in cases when fault occurs, or if it is considered beneficial (e.g., loss reduction), the topology is reconfigured by opening or closing the corresponding switches. 
The fact that traditional distribution networks are operated in radial mode to feed passive loads and the absence of generation, allows one to assume that power flows unidirectionally, from upstream medium voltage (MV) substations to loads. Consequently, voltage decreases within distribution feeders, depending on the power consumption. During peak hours, current increases considerably due to demand, and so does the voltage drop. In contrast, power demand decreases during valley hours and the voltage at the tail end of the feeder may be close to the value at the substation. As depicted in Figure 1, if the voltage is not controlled during peak hours, limits could be surpassed. Line drop compensation is then used to correct the voltage drop within the feeder and meet voltage limits. Substation transformers are typically on-load tap changers (OLTC) to adjust taps according to the state of the distribution network, i.e., taps are selected depending on the current that circulates downstream (see Figure 2). For instance, if the current measured is high, the power demand is high, and thus the voltage drop will be high. Considering feeder impedance, the most adequate tap is selected. In some cases, typically in rural areas, if a feeder is too long a voltage regulator is used to provide additional voltage drop compensation. It is basically an autotransformer equipped with an OLTC to increase voltage at the secondary winding [13].
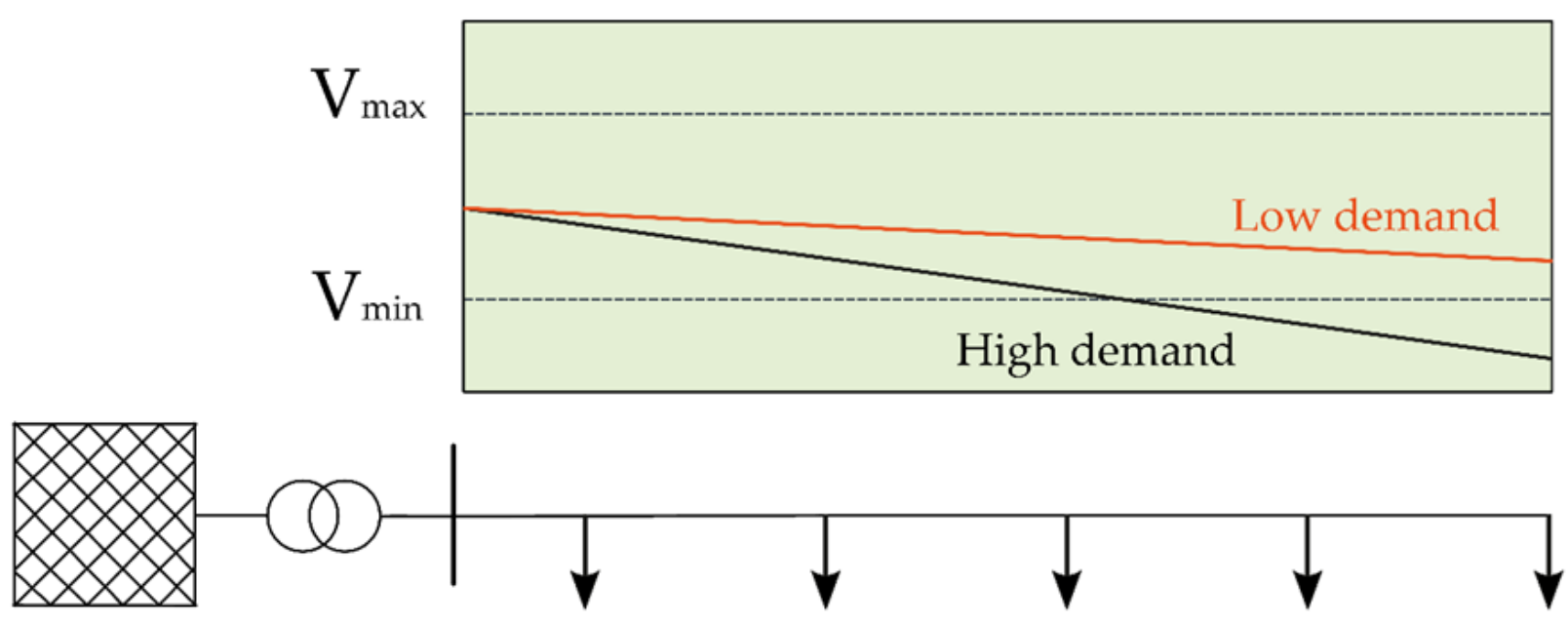

Figure 1. Voltage profile in traditional distribution networks without voltage regulation.
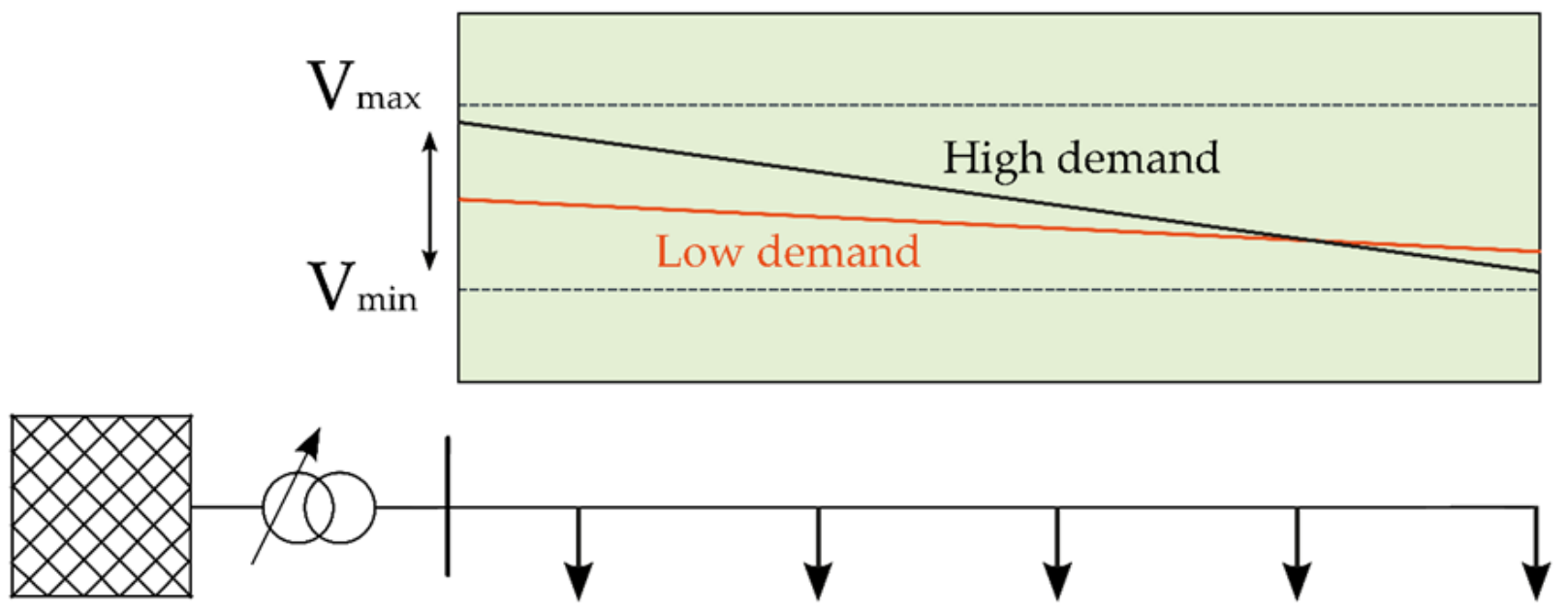

Figure 2. Voltage profile in traditional distribution networks with voltage regulation.

However, the voltage provided to the low voltage (LV) grids connected to the MV feeder depends on the proximity to the substation. Consumers close to the MV substation 
will be provided with higher voltage than consumers at the tail end of the feeder. Additionally, LV grids may have different line lengths and characteristics, and all loads must be fed with adequate voltage values. Therefore, MV / LV transformers are equipped with deenergized tap changers to correct for the expected voltage drop within LV lines. Note that OLTC transformers are not typically used due to the elevate number of LV feeders that implies a high associated cost.

Furthermore, reactive power compensation affects voltage control indirectly due to the reactance of lines. Although reactive power can be imported from transmission and subtransmission grids, this may lead to additional costs. Therefore, shunt capacitors are used to inject reactive power into the network and to feed distribution transformers, lines, and loads. According to the state of the system and its needs, the number of capacitor banks connected is increased or decreased in a discrete manner. Thus, capacitor banks are usually placed in MV substations to feed the downstream distribution network. Should the feeder be long, pole-mounted capacitor banks can be used to reduce power losses and thus the voltage drop. In addition, some consumers could install capacitor banks to correct their power factor, e.g., industries.

Regarding congestion management, this has not been considered in traditional distribution networks. During the planning stage, lines and transformers are sized considering the expected power consumption. As a matter of fact, repowering lines and replacing transformers is costly, thus lines and transformers are typically over-dimensioned to reduce the need for grid reinforcements.

To sum up, the operation of traditional distribution networks is simplified with respect to transmission, where the relatively low number of buses makes it feasible to monitor the complete system. Assuming that only loads are connected and thus power flows are unidirectional, distribution networks can be controlled through OLTC transformers and capacitor banks. In this way, the concept of fit and forget arises: first, distribution equipment is adjusted for the network considered; then, by monitoring some nodes, voltage can be controlled to meet the predetermined limits, and no issues will arise if the system is well-dimensioned.

\section{Centralized Control Strategies in Distribution Networks}

It is becoming increasingly urgent to develop more efficient technologies to reduce the share of fossil fuels in the energy mix. Renewable energies are gradually displacing fossilbased technologies [3], and a significant portion is increasingly connected at distribution networks thanks to their modularity and emission-free characteristics. However, DRES affect the classical operation of distribution networks, since these were conceived to supply loads, but not to have generation connected [14].

Traditional distribution networks were based on having only passive loads connected, thus making power flows unidirectional and with the voltage profile always descending due to voltage drop. Based on these assumptions, distribution networks were normally controlled through OLTC transformers, voltage regulators, and capacitor banks [10,15]. However, disperse generation results in bidirectional power flows, and the voltage at nodes where DRES are connected increases. As depicted in Figure 3, introducing DRES along the system makes the voltage profile become irregular, which could lead to overvoltage at certain nodes within the feeder, even if voltage at a MV substation is within bounds. As addressed in [10], presence of DRES can be considered as a net demand reduction if near loads still consume more power than DRES generate, provided no congestion arises. On the contrary, if generation is larger than consumption, the impact will depend on the relative position of the DRES with respect to loads, the state of the system, and the location within the feeder. Moreover, automatic voltage controllers of OLTC transformers and voltage regulators could estimate the voltage drop incorrectly if DRES are connected just downstream from them [15]. 

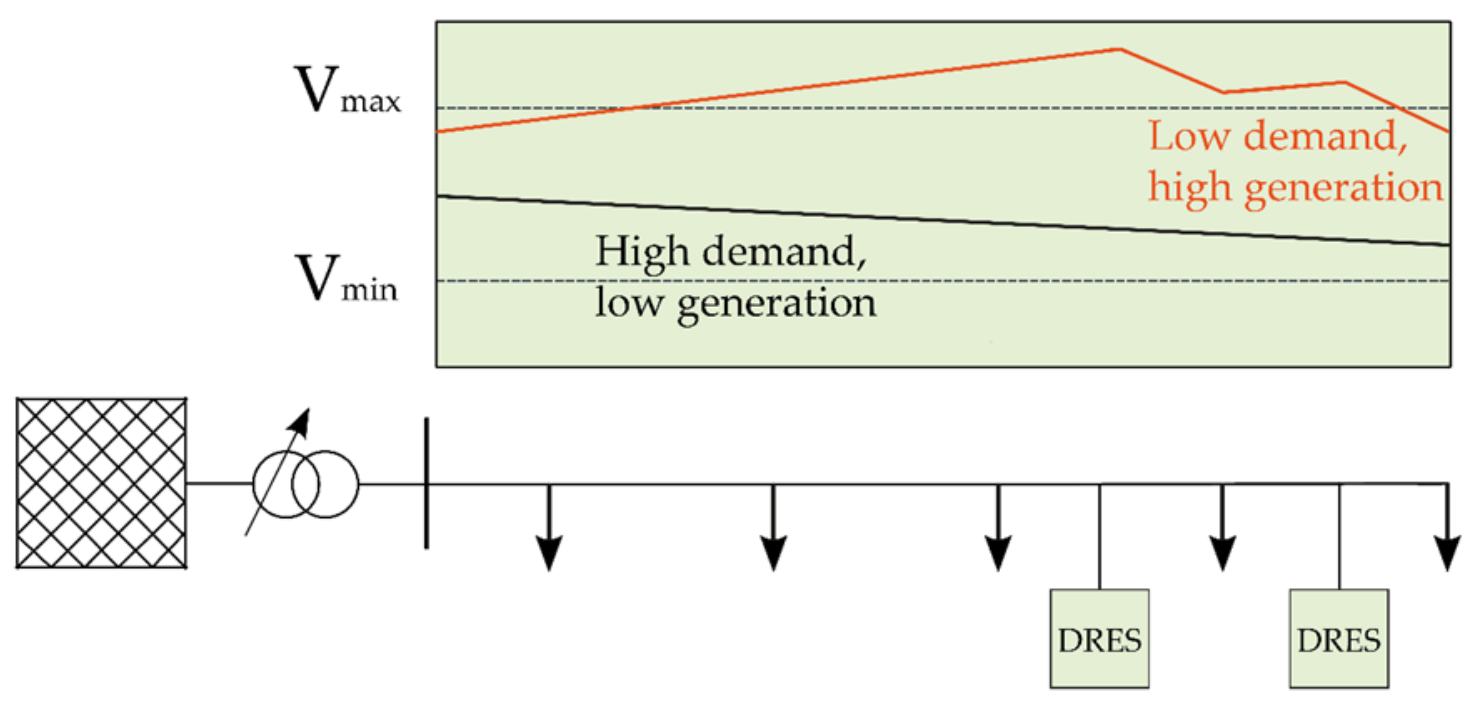

Figure 3. Voltage profile in active distribution networks.

PEVs are another developing trend that distribution networks need to face. Distribution networks were designed to supply passive consumers according to certain load estimations, e.g., increase in the number of habitants, $\mathrm{kW}$ per capita, etc. However, PEVs may represent larger loads than those considered during planning stages [11]. Power demand depends on the battery charging mode used, which can be classified into slow and fast according to the power level of the charger [11]. The slow-charging mode employs a small rate of charging power and thus requires long serving time. In that sense, the slow mode is typically left for residential use or roadside parking, since the low power consumption avoids large investments for grid reinforcement. Regarding the fast-charging mode, it reduces serving time considerably, at a cost of increasing power consumption. Naturally, this mode is the most attractive for end-users, since they do not need to plan the use of their PEV a day ahead; however, it results in extreme surges in demand, which may cause excessive voltage drops along with congestion in distribution lines and transformers. If no remedial actions are considered and vehicle charging is left uncontrolled, PEV penetration will be limited in comparison with the scenario where coordination strategies are considered [16].

Thanks to the converter-interface of DRES and PEV chargers, it is possible to minimize their impact on the grid. According to the control implemented, the setpoints of active power, reactive power, voltage, or frequency can be determined [17], allowing the development of different control strategies. For instance, in [16], PEV penetration is estimated in the benchmark grid IEEE-34 by considering PEVs placed randomly within subsequent iterations. If no charging strategy is employed and vehicles are charged in an uncoordinated manner, voltage violations arise for $30 \%$ of PEV penetrations. In contrast, if vehicles are coordinated and charging is optimized, voltages remain within bounds for that penetration level.

Furthermore, DRES make it possible to redefine electrical energy systems. Instead of having generation grouped and connected to transmission, these infrastructures can be simplified by bringing generation and demand closer. In that sense, the role of microgrids and virtual power plants arises. The former consists of the DRES, PEVs, and loads spread within the same area and has the ability to operate autonomously, connected to the rest of the system, or in an islanded mode [18]. In contrast, virtual power plants are not limited geographically [18] and provide a single operating profile to represent the corresponding subsystem [19].

Several controls have been developed to help increase DRES and PEV penetration. Particularly, centralized controls for real-time operation exchange of information between the available equipment and a modern distribution management system that performs the 
role of master, sending the appropriate control setpoints to each device after solving the corresponding algorithm. This type of methodology stands out by reaching more optimal scenarios when the whole system is considered. Within the remainder of this section, control techniques are presented for voltage control and congestion management.

\subsection{Review of Strategies for Voltage Control}

Traditional control strategies can be insufficient for maintaining voltages within bounds in the presence of DRES and PEVs. Whereas the load consumption makes voltages decrease, generation elevates them, leading to irregular profiles that could even have overvoltage and undervoltage in one feeder. Therefore, controlling the voltage at the upstream substation through transformer taps and shunt capacitors does not solve voltage problems in the network, because the overvoltage and undervoltage need opposite control actions. Even if controlling the voltage at the substation would be sufficient due to limited DRES and PEV generation, OLTC transformers would suffer from wear and tear because of the need of an elevated number of actions to correct voltages. To reduce the impact of DRES and PEVs, and employ traditional controls, an optimal real-time voltage regulation is proposed in [20] that results in relaxed tap operation.

The simplest strategies to maintain voltage within a bound is to curtail DRES generation to avoid overvoltage problems, or to limit PEV consumption to reduce excessive voltage drop. For instance, active power curtailment of photovoltaic inverters is employed in [21] to prevent overvoltages. Despite decreasing renewable energy production of certain DRES, both the installed capacity and the global energy yield increase. A similar approach is to distribute energy storage systems within the network to reduce the impact of DRES during peak generation, while providing power to reduce voltage drops due to peak loads, e.g., [22]. PEV batteries can be also used through coordinated charging strategies. In [23], the effect of uncontrolled charging is studied for a low voltage grid and a fuzzy management strategy is proposed. This considers as control variables the state of charge of PEVs, the charging delay time, and the distance between PEVs and the upstream substation, which is highlighted as a major factor due to line impedances.

However, only considering active power is intrinsically inefficient, since it affects energy and, consequently, end-users directly. As demonstrated in [10], in distribution levels voltage depends on both active and reactive power, due to the resistance and reactance components of lines, which also depend on the voltage level of the network [24]. Through volt/var controls, reactive power can then be used to reduce the use of active power and thus energy; i.e., using DRES or PEV chargers to inject reactive power increases the voltage for preventing undervoltage, whereas reactive power consumption reduces voltage and prevents overvoltage. As an example, the real-time control proposed in [25] optimizes nodal voltages to minimize voltage deviation by controlling the reactive power injected by photovoltaic inverters. Since this may reduce active power production, thus increasing operating costs, an economic compensation mechanism is proposed for this service.

Similarly, the authors in [26] developed a discrete coordinate descent algorithm based on sensitivities to solve volt/var control in the presence of DRES, whereas in [27] a rulebased method is proposed to complement traditional volt/var control and reduce the effect the fluctuations of associated with photovoltaic generators. Additionally, coordination with sub-transmission systems can be considered to optimally dispatch the use of the reactive power of DRES in conjunction with shunt devices [28]. In this case, the reactive power imported from higher voltage networks becomes another control variable, thus requiring improved communication with system operators.

The most effective and efficient controls come from considering both reactive and active power, because the associated cost of the latter is higher than the former due to its impact on energy. In that sense, active power should be used only in case reactive power is insufficient to correct voltage deviations. For instance, the method proposed in [29] employs the reactive power capability of photovoltaic inverters along with active power curtailment. An optimal power flow is used to improve the voltage magnitude and balance 
profiles, as well as minimizing network losses and generation costs. Similarly, the optimal power flow problem is also used in [30] for overvoltage mitigation due to DRES and to optimize network operations as well. This method includes a droop control mechanism in the optimal power flow to update DRES droop characteristics according to the needs of the system.

In contrast to methods that optimize a mathematical function, a centralized heuristic control is proposed in [31] to solve voltage problems. It is based on generic rules that can be tuned to comply with every grid code. By considering the state of the system, network limits, the availability of control variables, and the cost associated with control actions, the most appropriated action is determined in case a voltage violation is detected. This methodology employs sensitivities to set the relation between the available controls and electrical magnitudes, as engineers in control rooms that make decisions according to the system state and how they predict their control action will affect the voltages. Although sensitivity calculation needs much data from the network, sensitivities can be estimated through perturb-and-observe techniques [32].

In summary, to achieve voltage control in the network, different methods are employed: using traditional network elements, such as transformer taps and shunt capacitors; through optimal voltage regulation in real-time; by controlling reactive power using equipment, such as inverters, or algorithms; taking advantage of coordination with subtransmission systems; controlling both active and reactive power; by using algorithms to solve the optimal power flow in real-time; using heuristic methods; using energy storage systems; and through curtailing DRES generation.

\subsection{Review of Strategies for Congestion Management}

Overloads within distribution networks can be caused by DRES and PEVs, depending on their penetration. Different methods have been developed to manage congestion based on the infrastructure available in the network and through price signals that influence the behavior of demand.

\subsubsection{Network-Based Methods}

The methods that directly act on the network are those where the distribution system operator manages independently of the clients and aggregators. Among them are network reconfiguration, active and reactive power control [5], relations between distribution and transmission system operators, and energy storage systems, which may be connected in electrical facilities or belong to consumers [33].

Many distribution networks have loops that are operated radially instead of meshed. Therefore, network planning is simplified, but the benefits of having various paths to supply loads remain. Should a fault occur in one feeder, loads can be supplied through a different path by the same or another substation to increase system reliability and quality indexes. Reconfiguration is based on changing the states of switches in the network to modify the topology of the grid, alleviating lines and transformers, whilst reducing power losses. This can be performed both a day ahead and in real-time. The former should optimize power flows by considering consumption and generation forecasts, whereas the latter aims at correcting any deviations or the effects of unpredictable events. In this way, the decisionmaking process can be performed in a control room, but also automatically through control algorithms [34]. The changes in switch states can serve to support neighboring microgrids and redistributing power flow by closing the connection lines between them [35]. Similarly, DRES generation can be transferred between lines [36] during peak generation or transferred to energy storage systems [37].

The control of active power means a reduction of the demand, which entails affecting the clients. For instance, a curtailment technique is proposed in [38] to complement demand response when the available flexibility is insufficient. However, the control of reactive power implies increasing the transfer capacity [39], and, as addressed for voltage control strategies, actuations that affect reactive power are more efficient since active power directly 
impacts on the energy to be transmitted. If reactive power control is performed together with voltage regulation, congestion management can be improved [40].

Finally, regarding the coordination between distribution and transmission system operators, this is becoming more and more necessary. Transmission networks can benefit from the flexibility of distributed generation, on the one hand, and the distribution network from the active management of the transmission network, on the other hand [41]. Methods to implement this relationship have been developed for both day-ahead scheduling and real-time dispatch [42].

\subsubsection{Methods Based on Demand Response}

Through pricing mechanisms, it is intended to encourage savings or penalize the energy consumption of consumers to meet the needs of the system. The former can be achieved by means of economic incentives, so at certain times the consumer reduces his consumption or even stops consuming. The penalty is made by changing consumer habits. The latter is achieved through electricity price modifications [43]. The main elements that allow flexible demand management are PEVs and heat pumps, because their power consumption is high. In this way, power demand can be reduced at congested points and increased at others to alleviate any congestion [44]. In particular, the expected increase in PEVs has led to different charge control algorithm methods [45].

Demand response is usually day-ahead, although some methods are applied in realtime. Day-ahead dynamic tariffs aim to favor demand through a flexible pricing system that is established once the network conditions for the next day are known [46]. Distribution locational marginal pricing is a method like dynamic tariffs, but in this case, the tariff price for each consumer depends on the node where they are connected. This price will depend on the distributed generation and the distributed energy storage that exist [47].

Aggregators are a fundamental component in these methods, grouping consumers subject to demand response and simplifying the communication with the system operator [48]. Thus, the network capacity is assigned to the aggregators in the distribution grid capacity market to perform the optimization of demand response and communicate it the system operator, who can accept it or indicate the modifications to be made [49].

Real-time methods are those in which prices vary throughout the day. This is due to the possible changes that the system operator needs to introduce by having a much more accurate forecast than the day-ahead forecast that was initially available. Here, aggregators also play an important role. The intra-day shadow price method takes advantage of the flexibility of aggregators to optimize their capabilities throughout the day [50]. There is also the possibility that system operators buy flexibility from customers and aggregators to reduce demand at certain points in the network [51]. A case study is presented in [52], where the case of the existing network around the Amsterdam Arena stadium was studied by analyzing the technical aspects of availability.

\subsubsection{Combined methods}

The different methods of each of the categories can be applied separately; however, hybrid techniques present better results. Thus, they take advantage of the benefits of both techniques, while widening the scope of action. Moreover, in case one technique is exhausted, another can be still used. For example, if a network-based method is used first, it can be complemented with one based on demand response, so that prices are lower. In this way, the distribution system operator can resolve parts of the congestion with different methods [53-56].

There are also methods that take advantage of the different types of energy used by consumers, and the flexibility of the operation is improved. Thus, by making use of electricity, natural gas, cooling, and heat, the congestion in the network is resolved [57].

From an economic point of view, the first actions to be implemented should be those with no cost, i.e., network-based methods. In case further actions are required to eliminate the congestion problem, methods based on demand response should be used. If the 
problem persists, load shedding or power curtailment should be considered to avoid relay tripping.

In summary, congestion management is achieved in different ways: reactive power compensation improved by voltage regulation; network reconfiguration; managing available storage systems; by means of the coordination between distribution and transmission system operators; and through a pricing policy that encourages consumers to adapt their demand, so that they reduce their consumption as a result of a high energy price and stop consuming at certain times by granting them an incentive.

\section{Conclusions}

Distribution networks were conceived to supply geographically widespread loads. The higher number of consumers and the lower amount of energy to be distributed compared with transmission systems, led to planning and operating these systems mainly considering economic criteria. Operation and planning were simplified through the fit-andforget premise, which contrasts with the upcoming needs to deal with DRES and PEVs. Therefore, this paper analyzed the current state of distribution networks regarding voltage control and congestion management, how centralized controls help with increasing DRES and PEV penetration, and provided a classification of the techniques used.

Voltage control was based on the traditional voltage profile, which is always descending due to voltage drop, since only loads were present. The presence of DRES increases voltages at their connection nodes and surroundings, whereas PEVs result in high demands, thus increasing the voltage drop considerably. Additionally, congestion also arises because PEVs can increase power consumption during peak hours, or in cases where DRES generate too much power that is not consumed locally. However, developing control algorithms to dispatch and reschedule the available control variables, including these new actors, allows solving these voltage problems effectively.

Several studies and research reports shed light on techniques for solving these issues. In particular, centralized control algorithms allow considering the whole network and managing more information. Some authors have proposed simple methods based on only curtailing active power or rescheduling reactive power setpoints that increase DRES and PEV penetration compared to the scenario where coordinated actions are not considered. Other studies aimed at bringing systems to a state closer to the optimal by considering a wide range of control variables and combining the use traditional equipment, such as tap changers or shunt capacitors, with novel elements, such as DRES or PEVs. As a summary, a classification of the proposed methodologies for voltage control and congestion management is presented in Table 1.

Table 1. Methodologies applied for voltage control and congestion management.

\begin{tabular}{cc}
\hline Voltage Control & Congestion Management \\
\hline Traditional elements of the network & Reactive power compensation improved by voltage regulation \\
Optimal real-time voltage regulation & Network reconfiguration \\
Reactive power control using equipment & Managing available storage systems \\
Coordination with subtransmission systems & Coordination between distribution and transmission system operators \\
Active and reactive power control & Pricing policy that encourages consumers to adapt their demand \\
Optimal power flow resolution in real-time & \\
Use of heuristic methods & \\
Energy storage systems & \\
Curtail DRES generation & \\
\hline
\end{tabular}

Author Contributions: Conceptualization, F.J.Z.-S. and J.L.M.-R.; methodology, F.J.Z.-S. and J.L.M.-R.; validation, F.J.Z.-S., P.J.Z.-P. and J.L.M.-R.; formal analysis, F.J.Z.-S. and P.J.Z.-P.; investigation, F.J.Z.-S. and P.J.Z.-P.; resources, F.J.Z.-S. and P.J.Z.-P.; data curation, F.J.Z.-S. and P.J.Z.-P.; writing-original draft preparation, F.J.Z.-S. and P.J.Z.-P.; writing—review and editing, F.J.Z.-S., P.J.Z.-P. and J.L.M.-R.; 
visualization, F.J.Z.-S.; supervision, J.L.M.-R.; project administration, J.L.M.-R.; funding acquisition, J.L.M.-R. All authors have read and agreed to the published version of the manuscript.

Funding: This research was funded by the European Union's Horizon 2020 Research and Innovation Program under Agreement 764090, EASY-RES Project, and by the CERVERA Research Program of CDTI, the Industrial and Technological Development Centre of Spain, through the Research Project HySGrid+ under Grant CER-20191019.

Conflicts of Interest: The authors declare no conflict of interest.

\section{References}

1. Leighty, W.; Holbrook, J.H. Alternatives to Electricity for Transmission, Firming Storage, and Supply Integration for Diverse, Stranded, Renewable Energy Resources: Gaseous Hydrogen and Anhydrous Ammonia Fuels via Underground Pipelines. Energy Procedia 2012, 29, 332-346. [CrossRef]

2. Tazvinga, H.; Thopil, M.; Numbiand, P.B.; Adefarati, T. Distributed Renewable EnergyTechnologies. In Handbook of Distributed Generation Electric Power Technologies, Economics and Environmental Impacts, 1st ed.; Bansal, R., Ed.; Springer International Publishing: Cham, Switzerland, 2017.

3. IEA. World Energy Outlook 2020; IEA: Paris, France, 2020. Available online: https://www.iea.org/reports/world-energy-outlook2020 (accessed on 4 July 2021).

4. Arcos-Vargas, A.; Cansino, J.M.; Román-Collado, R. Economic and environmental analysis of a residential PV system: A profitable contribution to the Paris agreement. Renew. Sustain. Energy Rev. 2018, 94, 1024-1035. [CrossRef]

5. Huang, S.; Wu, O.; Liu, Z.; Nielsen, A.H. Review of congestion management methods for distribution networks with high penetration of distributed energy resources. In Proceedings of the 5th IEEE PES Innovative Smart Grid Technologies Europe (ISGT Europe), Istanbul, Turkey, 12-15 October 2014. [CrossRef]

6. Council of European Energy Regulators. CEER Report on Power Losses; Council of European Energy Regulators: Brussels, Belgium, 2017.

7. Wang, Y.; Tan, K.T.; Peng, X.Y.; So, P.L. Coordinated control of distributed energy-storage systems for voltage regulation in distribution networks. IEEE Trans. Power Deliv. 2016, 31, 1132-1141. [CrossRef]

8. Penisa, X.N.; Castro, M.T.; Pascasio, J.D.A.; Esparcia, E.A., Jr.; Schmidt, O.; Ocon, J.D. Projecting the price of lithium-ion NMC battery packs using a multifactor learning curve model. Energies 2020, 13, 5276. [CrossRef]

9. Larminie, J.; Lowry, J. Types of Electric Vehicles-EV Architecture. In Electric Vehicle Technology Explained, 2nd ed.; John Wiley \& Sons: Hobokeen, NJ, USA, 2012.

10. Zarco-Soto, F.J.; Martínez-Ramos, J.L.; Zarco-Perinán, P.J. Voltage Control in Active Distribution Networks. In Power Quality in Modern Power Systems, 1st ed.; Sanjeevikumar, P., Sharmeela, C., Holm-Nielsen, J.B., Sivaraman, P., Eds.; Academic Press: London, UK, 2020; pp. 193-217. [CrossRef]

11. Zheng, Y.; Niu, S.; Shang, Y.; Shao, Z.; Jian, L. Integrating plug-in electric vehicles into power grids: A comprehensive review on power interaction mode, scheduling methodology and mathematical foundation. Renew. Sustain. Energy Rev. 2019, 112, 424-439. [CrossRef]

12. Martínez-Ramos, J.L.; Conejo, A.J. Optimal and secure operation of transmission systems. In Electric Energy Systems: Analysis and Operation, 2nd ed.; Gómez-Expósito, A., Conejo, A.J., Cañizares, C., Eds.; CRC Press: Boca Raton, FL, USA, 2018; pp. $237-277$.

13. Kersting, W.H. Distribution System Modeling and Analysis, 3rd ed.; CRC Press: Boca Raton, FL, USA, 2018 ; pp. $237-277$.

14. Masters, C.L. Voltage rise the big isuue when connecting embedded generation to long $11 \mathrm{kV}$ overhead lines. Power Eng. J. 2002, 16, 5-12. [CrossRef]

15. Barker, P.P.; Mello, R.W. Determining the Impact of Distributed Generation on Power Systems: Part 1-Radial Distribution Systems. In Proceedings of the 2000 Power Engineering Summer Meeting (cat. No,00CH37134), Seattle, WA, USA, 16-20 July 2000; Volume 3, pp. 1645-1656. [CrossRef]

16. Clement-Nyns, K.; Haesen, E.; Driesen, J. The Impact of Charging Plug-In Hybrid Electric Vehicles on a Residential Distribution Grid. IEEE Trans. Power Syst. 2010, 25, 371-380. [CrossRef]

17. Rocabert, J.; Luna, A.; Blaabjerg, F.; Rodríguez, P. Control of power converters in AC microgrids. IEEE Trans. Power Electron. 2012, 27, 4734-4749. [CrossRef]

18. Asmus, P. Microgrids, Virtual Power Plants and Our Distributed Energy Future. Electr. J. 2010, 23, 78-82. [CrossRef]

19. Pudjianto, D.; Ramsay, C.; Strbac, G. Virtual power plant and system integration of distributed energy resources. IET Renew. Power Gener. 2007, 1, 10-16. [CrossRef]

20. Azzouz, M.A.; Farag, H.E.; El-Saadany, E.F. Real-Time fuzzy voltage regulation for distribution networks incorporating high penetration of renewable sources. IEEE Syst. J. 2017, 11, 1702-1711. [CrossRef]

21. Tonkoski, R.; Lopes, L.A.C.; El-Fouly, T.H.M. Coordinated Active Power Curtailment of Grid Connected PV Inverters for Overvoltage Prevention. IEEE Trans. Sustain. Energy 2011, 2, 139-147. [CrossRef]

22. Zeraati, M.; Golshan, M.E.H.; Guerrero, J.M. Distributed control of battery energy storage systems for voltage regulation in distribution networks with high PV penetration. IEEE Trans. Smart Grid 2018, 9, 3582-3593. [CrossRef] 
23. Boglou, V.; Karavas, C.S.; Arvanitis, K.; Karlis, A. A Fuzzy Energy Management Strategy for the Coordination of Electric Vehicle Charging in Low Voltage Distribution Grids. Energies 2020, 13, 3709. [CrossRef]

24. Gómez-Expósito, A.; Alvarado, F.L. Load flow. In Electric Energy Systems: Analysis and Operation, 2nd ed.; Gómez-Expósito, A., Conejo, A.J., Cañizares, C., Eds.; CRC Press: Boca Raton, FL, USA, 2018; pp. 99-132.

25. Cagnano, A.; Tuglie, E. Centralized voltage control for distribution networks with embedded PV systems. Renew. Energy 2015, 76, 173-185. [CrossRef]

26. Jabr, R.A.; Dzafic, I. Sensitivity-Based discrete coordinate-descent for volt/var control in distribution networks. IEEE Trans. Power Syst. 2016, 31, 4670-4678. [CrossRef]

27. Jabr, R.A. Robust Volt/VAr Control with Photovoltaics. IEEE Trans. Power Syst. 2019, 24, 2401-2408. [CrossRef]

28. Ke, X.; Samaan, N.; Holzer, J.; Huang, R.; Vyakaranam, B.; Vallem, M.; Elizondo, M.; Lu, N.; Zhu, X.; Werts, B.; et al. Coordinative real-time sub-transmission volt-var control for reactive power regulation between transmission and distribution systems. IET Gener. Transm. Distrib. 2019, 13, 2006-2014. [CrossRef]

29. Su, X.; Masoum, M.A.S.; Wolfs, P.J. Optimal PV inverter reactive power control and real power curtailment to improve performance of unbalanced four-wire LV distribution networks. IEEE Trans. Sustain. Energy 2014, 5, 967-977. [CrossRef]

30. Kryonidis, G.C.; Kontis, E.O.; Chrysochos, A.I.; Demoulias, C.S.; Papagiannis, G.K. A Coordinated Droop Control Strategy for Overvoltage Mitigation in Active Distribution Networks. IEEE Trans. Smart Grid 2018, 9, 5260-5270. [CrossRef]

31. Martínez-Ramos, J.L.; Zarco-Soto, F.J.; Marano-Marcolini, A.; Zarco-Periñán, P.J.; Trigo-García, A.L. Coordination of distributed energy resources to solve voltage problems in distribution networks. In Proceedings of the International Conference on Smart Energy Systems and Technology (SEST), Sevilla, Spain, 10-12 September 2018; pp. 1-6. [CrossRef]

32. Tamp, F.; Ciufo, P. A sensitivity analysis toolkit for the simplification of MV distribution network voltage management. IEEE Trans. Smart Grid 2014, 5, 559-568. [CrossRef]

33. Jafarian, M.; Scherpen, J.M.A.; Loeff, K.; Mulder, M.; Aiello, M. A combined nodal and uniform pricing mechanism for congestion management in distribution power networks. Electr. Power Syst. Res. 2020, 180, 106088. [CrossRef]

34. Vandoorn, T.L.; Vyver, J.V.; Gevaert, L.; Degroote, L.; Vandevelde, L. Congestion control algorithm in distribution feeders: Integration in a distribution management system. Energies 2015, 8, 6013-6032. [CrossRef]

35. Shania, F.; Ghosh, A. Coupling neighboring microgrids for overload management based on dynamic multicriteria decision-making. IEEE Trans. Smart Grid 2015, 8, 969-983. [CrossRef]

36. Bilibin, I.; Capitanescu, F. Overloads management in active radial distribution systems: An optimization approach including network switching. In Proceedings of the IEEE Grenoble Conference, Grenoble, France, 16-20 June 2013; pp. 1-5. [CrossRef]

37. Pashajavid, E.; Shahnia, F.; Ghosh, A. Overload management of autonomous microgrids. In Proceedings of the 11th IEEE International Conference on Power Electronics and Drive Systems, Sydney, Australia, 9-12 June 2015; pp. 73-78. [CrossRef]

38. Haque, A.N.M.M.; Rahman, M.T.; Nguyen, P.H.; Bliek, F.W. Smart curtailment for congestion management in LV distribution network. In Proceedings of the 2016 IEEE Power and Energy Society General Meeting (PESGM), Boston, MA, USA, 17-21 July 2016; pp. 1-5. [CrossRef]

39. Andersen, P.B.; Hu, J.; Heussen, K. Coordination strategies for distribution grid congestion management in a Multi-Actor, Multi-Objective Setting. In Proceedings of the 3rd IEEE PES Innovative Smart Grid Technologies Conference Europe (ISGT Europe), Berlin, Germany, 14-17 October 2012. [CrossRef]

40. Viawan, F.A.; Karlsson, D. Voltage and reactive power control in systems with synchronous machine-based distributed generation. IEEE Trans. Power Deliv. 2008, 23, 1079-1087. [CrossRef]

41. Hadush, S.Y.; Meeus, L. DSO-TSO cooperation issues and solutions for distribution grid congestion management. Energy Policy 2018, 120, 610-621. [CrossRef]

42. Evangelopoulos, V.A.; Avramidis, I.I.; Georgilakis, P.S. Flexibility services management under uncertainties for power distribution systems: Stochastic scheduling and predictive real-time dispatch. IEEE Access 2020, 8, 38855-38871. [CrossRef]

43. Shen, F.; Wu, Q.; Huang, S.; Chen, X.; Liu, H.; Xu, Y. Two-tier demand response with flexible demand swap and transactive control for real-time congestion management in distribution networks. Int. J. Electr. Power Energy Syst. 2020, 114, 105339. [CrossRef]

44. Ghazvini, M.A.F.; Lipari, G.; Pau, M.; Poci, F.; Monti, A.; Soares, J.; Castro, R.; Vale, Z. Congestion management in active distribution networks through demand response implementation. Sustain. Eenrgy Grids Netw. 2019, 17, 100185. [CrossRef]

45. Veloso, C.G.; Rauma, K.; Fernández, J.; Rehtanz, C. Real-time control of plug-in electric vehicles for congestion management of radial LV networks: A comparison of implementations. Energies 2020, 13, 4227. [CrossRef]

46. Haque, N.; Tomar, A.; Nguyen, P.; Pemen, G. Dynamic tariff for day-ahead congestion management in agent-based LV distribution networks. Energies 2020, 13, 318. [CrossRef]

47. Li, R.; Wu, Q.; Oren, S.S. Distribution locational marginal pricing for optimal electric vehicle charging management. IEEE Trans. Power Syst. 2014, 29, 203-211. [CrossRef]

48. Oureilidis, K.; Malamaki, K.N.; Gallos, K.; Tsitsimelis, A.; Dikaiakos, C.; Gkavanoudis, S.; Cvetkovic, M.; Mauricio, J.M.; MazaOrtega, J.M.; Martinez-Ramos, J.L.; et al. Ancillary Services Market Design in Distribution Networks: Review and Identification of Barriers. Energies 2020, 13, 917. [CrossRef]

49. Verzijlbergh, R.A.; Vries, L.J.; Lukszo, Z. Renewable energy sources and responsive demand. Do we need congestion management in the distribution grid? IEEE Trans. Power Syst. 2014, 29, 2119-2128. [CrossRef] 
50. Biegel, B.; Andersen, P.; Stoustrup, J.; Bendtsen, J. Congestion management in a smart grid via shadow prices. In Proceedings of the 8th IFAC Symposium on Power Plant and Power System Control, Toulouse, France, 2-5 September 2012; pp. 518-523. [CrossRef]

51. Huang, S.; Wu, Q. Dynamic subsidy method for congestion management in distribution networks. IEEE Trans. Smart Grid 2016, 9, 2140-2151. [CrossRef]

52. Kuiken, D.; Más, H.F.; Ghasemi, M.H.; Blaauwbroek, N.; Vo, T.H.; Klauw, T.; Nguyen, P.H. Energy flexibility from large prosumers to support distribution system operation-A technical and legal case study on the Amsterdam ArenA stadium. Energies 2018, 11, 122. [CrossRef]

53. Shen, F.; Huang, S.; Wu, Q.; Repo, S.; Xu, Y.; Ostergaard, J. Comprehensive congestion management for distribution networks based on dynamic tariff, reconfiguration, and re-profiling product. IEEE Trans. Smart Grid 2019, 10, 4795-4805. [CrossRef]

54. Kulmala, A.; Alonso, M.; Repo, S.; Amaris, H.; Moreno, A.; Mehmedalic, J.; Al-Jassim, Z. Hierarchical and distributed control concept for distribution network congestion management. IET Gener. Transm. Distrib. 2017, 11, 665-675. [CrossRef]

55. Huang, S.; Wu, Q.; Cheng, L.; Liu, Z. Optimal reconfiguration-based dynamic tariff for congestion management and line loss reduction in distribution network. IEEE Trans. Smart Grid 2016, 7, 1295-1303. [CrossRef]

56. Luo, E.; Cong, P.; Lu, H.; Li, Y.F.; Ghosh, A. Two-stage hierarchical congestion management method for active distribution networks with multi-type distributed energy resources. IEEE Access 2020, 8, 109309-109320. [CrossRef]

57. Hu, J.; Liu, X.; Shahidehpour, M.; Xia, S. Optimal operation of energy hubs with large-scale distributed energy resources for distribution network congestion management. IEEE Trans. Sustain. Energy 2021. [CrossRef] 